\title{
A Comparative Statistical Analysis on the Incidence of Developmental, Inflammatory and Neoplastic Odontogenic Cysts-A Single Center Retrospective Analysis from Italy
}

\author{
Antonio Barresi ${ }^{1}$, Giacomo Oteri ${ }^{1}{ }^{(}$, Angela Alibrandi ${ }^{2}$, Matteo Peditto ${ }^{1, *} \mathbb{C}$, Silvia Rapisarda ${ }^{1}$, \\ Roberta Cardia $^{3}$, Antonia Marcianò ${ }^{4}\left(\mathbb{D}\right.$ and Maria Lentini ${ }^{3}$ \\ 1 Department of Biomedical, Dental Science and Morphological and Functional Images, Dental School, \\ University of Messina, 98123 Messina, Italy; barresia@unime.it (A.B.); oterig@unime.it (G.O.); \\ srapisa@hotmail.it (S.R.) \\ 2 Department of Economics, University of Messina, 98123 Messina, Italy; angela.alibrandi@unime.it \\ 3 Department of Human Pathology of Adult and Developmental Age, University of Messina, \\ 98123 Messina, Italy; robertacardia87@hotmail.it (R.C.); maria.lentini@unime.it (M.L.) \\ 4 Department of Clinical and Experimental Medicine, University of Messina, 98123 Messina, Italy; \\ antmarciano@unime.it \\ * Correspondence: mpeditto@unime.it
}

Received: 14 December 2020; Accepted: 8 January 2021; Published: 21 January 2021

\begin{abstract}
The aim of this study was a comparative statistical analysis of three categories of maxillary odontogenic cysts, evaluating frequency in relation to localization (mandibular or maxillary region), age and gender of patients. The study was a retrospective cohort study conducted at the University Hospital of Messina. Three hundred and fifty-six maxillary odontogenic cysts were classified into 283 inflammatory, 43 developmental and 30 neoplastic cysts. Female patients are more affected by developmental odontogenic cysts, while male patients are more affected by inflammatory odontogenic cysts. Both the mandibular and maxillary regions were affected mainly by inflammatory odontogenic cysts; no significantly statistic relationship was found between lesions and age. A significant association between odontogenic cyst lesions and patient gender was found. No significant association between histological features of lesion and age of patient was observed, nor subtype of odontogenic disease and localization (mandibular or maxillary).
\end{abstract}

Keywords: odontogenic cysts; epidemiology; statistical analysis

\section{Introduction}

Maxillary cysts, irrespectively of regional distribution (mandibular or maxillary), represent the most frequent bone cysts and by definition are lined by epithelium. According to the different origin of epithelial lining, they are classified into two-main groups: odontogenic and non-odontogenic cysts; cystic spaces without epithelial lining represent pseudocysts [1-5]. This subdivision is supported by studies on the distribution of cytokeratins in the epithelial lining. Cytokeratins are cytoplasmic strands, represented by at least 19 different polypeptides, which represent the main structural proteins of all epithelial cells. It appears that all structures deriving from odontogenic epithelium have a superimposable cytokeratine content [6]. Odontogenic cysts represent the most frequently found odontogenic intra-osseous lesions that affect the mandibular and maxillary regions and are histologically characterized by a fibrous wall and a lining deriving from epithelial residue of the tooth-forming organ. According to the 4th edition of the WHO classification, odontogenic cysts can be classified 
into three groups: inflammatory, developmental and neoplastic cysts [1,2]. A significant change concerning type of odontogenic cysts is the reincorporation of odontogenic keratocysts and calcifying odontogenic cysts in the cyst classification when they were classified in 2005 as neoplasms [1,7]. Inflammatory cysts represent the most common odontogenic lesions and are always associated to a necrotic tooth. Radicular cysts represent the most common type (Figure 1) [1], which, in the majority of the cases, are localized in the radicular apex and arise from the fusion of the apical granuloma and the epithelial residue of Malassez. Generally, these lesions are asymptomatic and are found during a routine radiographic exam; radiographically, they present as a well-defined round radiolucency at the root apex. Occasionally, due to increased size, they expand the alveolar bone and, rarely, can produce nerve compression or sinusitis by emptying into a maxillary sinus or can penetrate the cortical bone appearing like a bluish, submucosal swelling [8]. Histologically, they are characterized by a non-keratinized stratified squamous epithelium lining a chronically inflamed fibrous capsule. Developmental cysts are the second group of intra-osseous cysts. They originate from the enamel epithelium and are always associated with an unerupted tooth (third mandibular molar in most cases) making contact with the cement-enamel junction. Commonly, these lesions are asymptomatic and painless, unless there is a secondary inflammation and are found during a routine radiographic exam or searching for a cause for an unerupted deciduous tooth. Dentigerous cysts are the most frequent type (Figure 2) [1]. Radiographically, they present as well-defined unilocular radiolucency associated with the crown of an unerupted tooth often displaced from its original seat [9]. Histologically, they are characterized by a thin non-keratinized stratified squamous epithelium or cuboidal epithelium, with frequent mucous metaplasia, supported by a fibrous capsule free from inflammation, unless there has been secondary inflammation [1]. Neoplastic cysts represent intra-osseous lesions arising from the dental foil; generally they are associated to a tooth and are characterized by invasiveness and high rate of recurrences, the most common being cystic ameloblastoma (Figure 3) [1]. Radiographically, cystic ameloblastoma present as a well- defined unilocular radiolucency, often associated to a third mandibular molar. Histologically, it presents an ameloblastomatous epithelium characterized by a basal layer of columnar cells with polarization of hyperchromic nuclei distal from the basal lamina, covered by a loose, vacuolated layer of stellate epithelial cells [1]. The different pathogenetic aspects of the three types of odontogenic cysts led us to hypothesize the existence of a correlation between each subtype and the demographic features of the affected patients, as well as the existence of a close relationship with the site of onset, mandibular or maxillary. A retrospective cohort study was conducted at the Department of Human Pathology, Messina University hospital, to perform a comparative statistical analysis of the three categories of maxillary odontogenic cysts (inflammatory, developmental and neoplastic) evaluating frequency in relation to region (mandibular or maxillary), age and gender of the affected patients. 


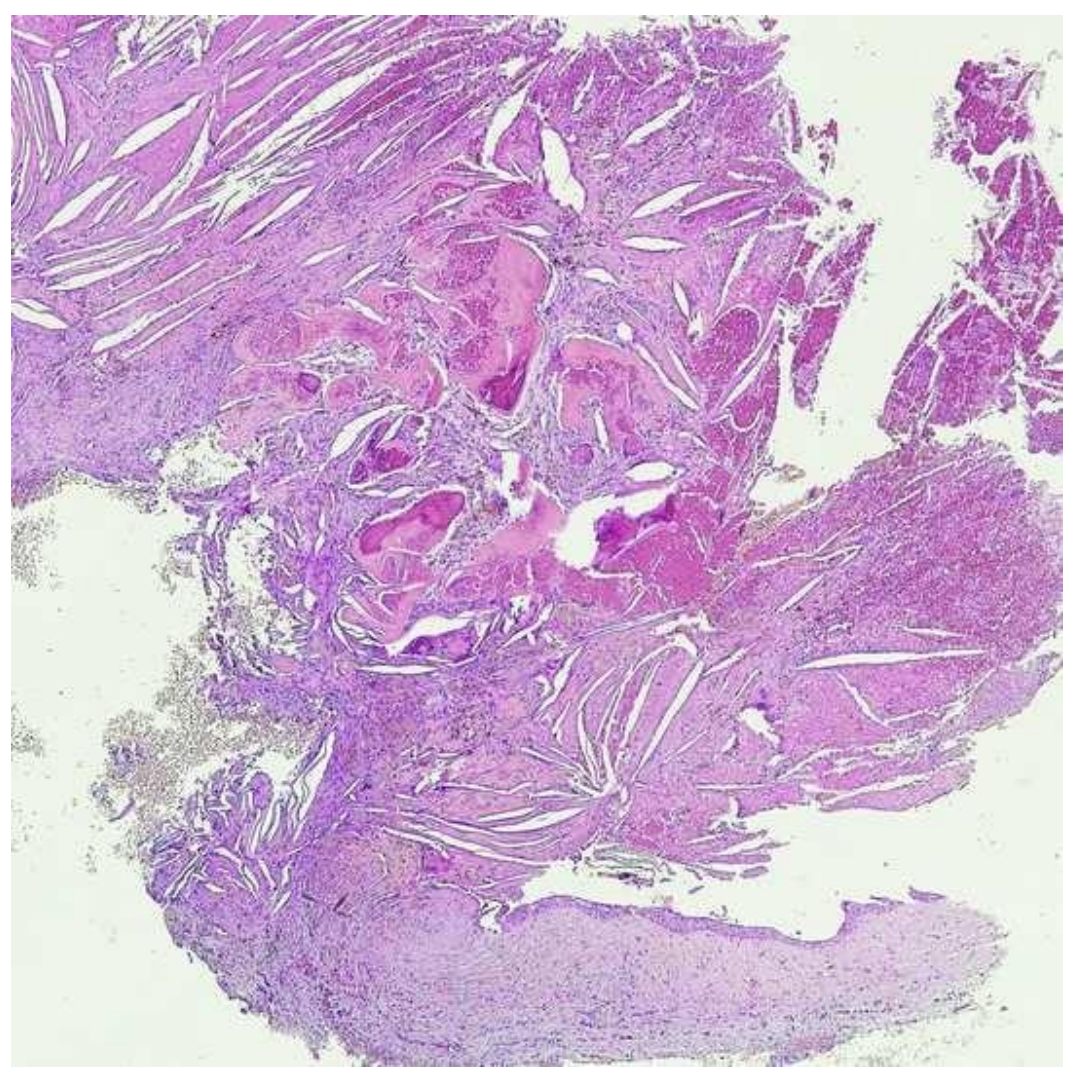

Figure 1. Histopathologic features of radicular cyst (Hematoxylin-Eosin, $4 \times$ ).

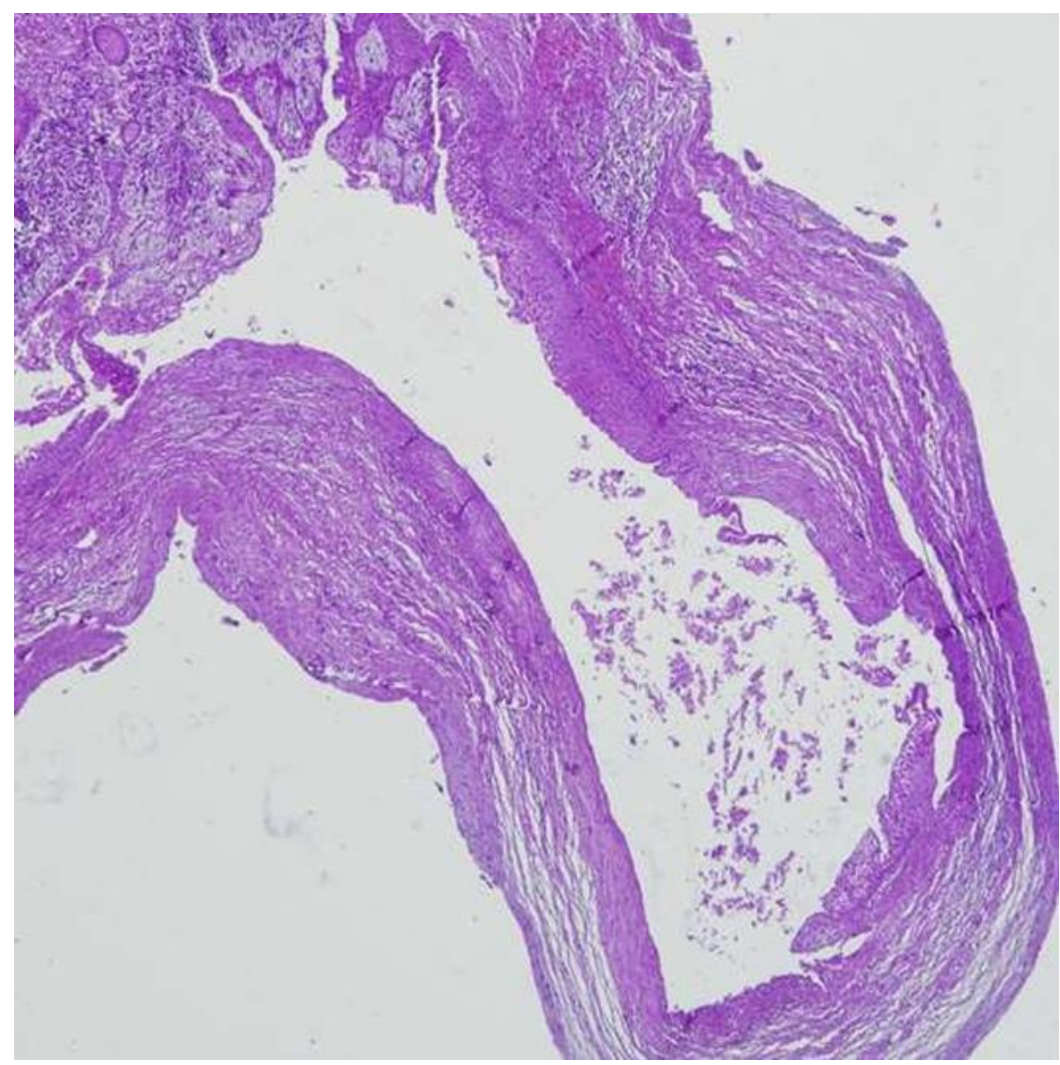

Figure 2. Histopathologic features of dentigerous cyst (Hematoxylin-Eosin, $4 \times$ ). 


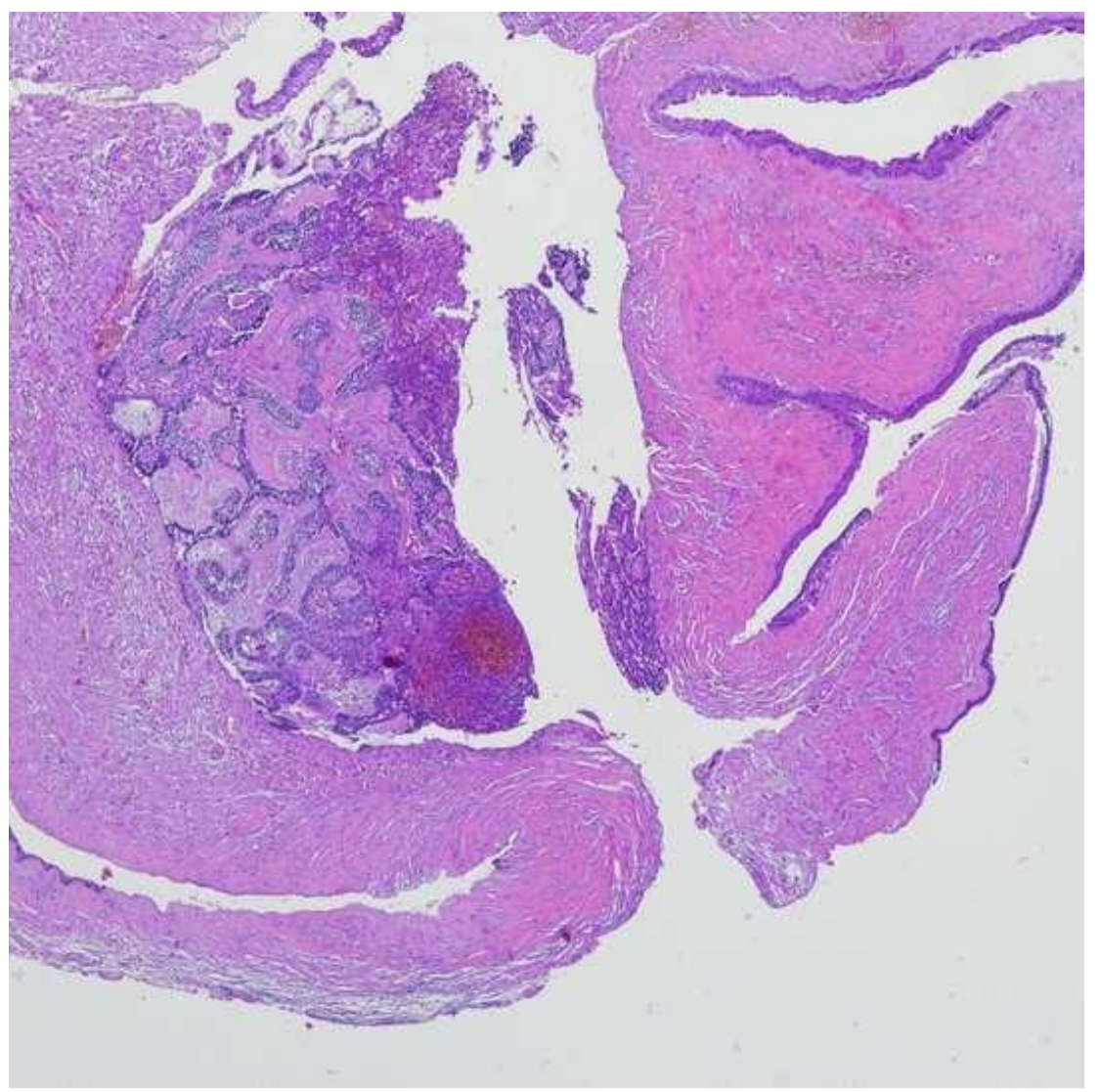

Figure 3. Histopathologic features of cystic ameloblastoma (Hematoxylin-Eosin, $4 \times$ ).

\section{Materials and Methods}

The medical files of all patients with odontogenic maxillary cysts diagnosed at the Department of Human Pathology (University of Messina) between 2006 and 2016 were retrieved. Histological diagnoses were performed according to the 4th edition of the WHO classification [1]. Maxillary odontogenic cysts were categorized into three groups, inflammatory, developmental and neoplastic cyst, independently of subtype; maxillary pseudocysts and non-odontogenic cysts were excluded. Demographic data from each patient regarding age, gender and regional distribution (mandibular and/or maxillary) were collected. Patient data were analyzed according to the histopathological features of the lesions and underwent statistical analysis. SPSS version 17.0 statistical software (SPSS Inc., Chicago, IL, USA) was used to analyze data. $P<0.05$ two sided was considered statistically significant. For each group of odontogenic cysts (inflammatory, developmental, neoplastic) the numerical variable (age) was expressed as mean, standard deviations (SD), median and range (minimum and maximum) and the categorical variables (gender and region) as count and percentage. A non-parametric approach was adopted as the sample size was small and the numerical variables were not normally distributed, as verified by the Kolmogorov Smirnov test. $\chi^{2}$ test was used to examine the relationship between categorical variables (gender and region) and lesions. Kruskall Wallis test was applied to evaluate the existence of statistically significant differences among three groups regarding age

\section{Results}

The 356 total cases were classified as follows: 283 (79.5\%) inflammatory, 43 (12.1\%) developmental and $30(8.4 \%)$ neoplastic odontogenic cysts. (Table 1). Every cyst belonging to the neoplastic was classified as unicystic ameloblastoma. Among patients with inflammatory odontogenic cysts, 208 (73.5\%) were male patients. Regarding anatomic site, the mandibular region was affected in $58.7 \%$ of cases and the maxillary region in $41.3 \%$. Mean age was $47.72 \pm 17.05$, median was 50 , minimum age 
was 6 and maximum was 88. Out of 43 developmental odontogenic cysts, 23 (53.5\%) patients were male. Regarding region, the mandibular region was affected in $60.5 \%$ of cases and the maxillary region in $39.5 \%$. Mean age was $65 \pm 17.78$, median was 46, minimum age was 8 and maximum 75 . Out of 30 neoplastic odontogenic cysts, $20(66.7 \%)$ patients were male. Regarding the site, the mandibular region was affected in $66.7 \%$ of cases and the maxillary region in $33.3 \%$. Mean age was $41.8 \pm 15.21$, the median was 40 , the minimum age was 16 and the maximum 80 . Analyzing the association between lesions and gender, the most frequently found lesion among females was developmental odontogenic cyst $(46.5 \%)$, while among males the most frequently found lesion was inflammatory odontogenic cyst (73.5\%). This result proved significant at chi square $(\chi 2)$ test $(p=0.024)$. Examining the association between lesions and region, both the mandibular and maxillary region were affected above all by inflammatory odontogenic cysts but not in a significant way $(p=0.691)$. On relating different histological features to age, the Kruskall-Wallis test was applied but it was not significant $(p=0.102)$, showing no relationship between the considered variables (Tables 2 and 3).

Table 1. Classification of studied cystic lesions.

\begin{tabular}{ccc}
\hline & Frequency & Proportion $\%$ \\
\hline IOC & 283 & 79.5 \\
DOC & 43 & 12.1 \\
NOC & 30 & 8.4 \\
Total & 356 & 100
\end{tabular}

IOC, inflammatory odontogenic cysts; DOC, developmental odontogenic cysts; NOC, neoplastic odontogenic cysts.

Table 2. Demographic characteristic.

\begin{tabular}{ccccc}
\hline & IOC & DOC & NOC & $p$ Value \\
\hline Age, year (mean \pm SD) & $47.72 \pm 17.05$ & $44.65 \pm 17.78$ & $41.8 \pm 15.21$ & 0.102 \\
Gender, $n$ & & & & 0.024 \\
Male & $208(73.5 \%)$ & $23(53.5 \%)$ & $20(66.7 \%)$ & \\
Female & $75(26.5 \%)$ & $20(46.5 \%)$ & $10(33.3 \%)$ & \\
\hline
\end{tabular}

IOC, inflammatory odontogenic cysts; DOC, developmental odontogenic cysts; NOC, neoplastic odontogenic cysts; $\mathrm{SD}$, standard deviation.

Table 3. Clinical distribution of studied cystic lesions.

\begin{tabular}{ccccc}
\hline Region Value & IOC & DOC & NOC & $p$ Value \\
\hline Mandibular & $166(58.7 \%)$ & $26(60.5 \%)$ & $20(66.7 \%)$ & 0.691 \\
Maxillary & $117(41.3 \%)$ & $17(39.5 \%)$ & $10(33.3 \%)$ & \\
\hline
\end{tabular}

IOC, inflammatory odontogenic cysts; DOC, developmental odontogenic cysts; NOC, neoplastic odontogenic cysts.

\section{Discussion}

Maxillary odontogenic cysts are characterized by different pathogenetic profiles [1] Knowledge of clinical features, such as incidence can be crucial for correct diagnosis. The current study, performed in a single institution, aimed to assess possible correlations between each group of odontogenic cysts and demographic data that is, age, gender and regional distribution (mandibular and/or maxillary. According to our data, odontogenic cysts are more common in males. This result is in line with data reported in literature; the most frequent odontogenic cyst reported in literature indicates radicular cyst as the most frequent inflammatory cyst [8-10]. Out of 356 total cases, inflammatory odontogenic cysts are predominant with $79.5 \%$ (283), of which $73.5 \%$ of patients (208) were males $(\mathrm{M}: \mathrm{F}=2.7: 1)$; these data are in agreement with other similar studies [11-22], although different results were found from other authors [23-28]. The higher incidence of inflammatory odontogenic cysts in males (73.5\%), compared to females $(26.5 \%)$, induces one to think that the difference is related to the fact that men are more likely to neglect oral hygiene $[11,17,19,20,22]$. The inflammatory nature of the lesion and 
the association with dental necrosis explains the infectious origin and this can be related to poor oral hygiene which is lower in males. Regarding the anatomic site, the mandibular region was affected by inflammatory odontogenic cysts in $58.7 \%$ of cases and the maxillary region in $41.3 \%$, in agreement with other studies by Avelar RL et al. [15] and Soluk Tekkesin M et al. [27]. However, these data are not completely in line with the updated literature; other studies found that the maxillary region was more affected by inflammatory odontogenic cysts than the mandibular region. The mean age of patients affected by inflammatory odontogenic cysts was almost 47 years old and similar data have been found in other studies present in literature. [11-28] Out of 43 developmental odontogenic cysts, $53.5 \%$ of patients (23) were males (M:F 1.1:1). Again, it has been found that this type of odontogenic cyst presented a higher incidence in males and this data is confirmed in agreement with a high number of similar studies [12-25,29-31]. Only in few other studies [21,26-28,32,33] the results demonstrated that developmental odontogenic cysts affected more females than males. Nevertheless, regarding the relationship between type of odontogenic cyst and gender, a statistically significant relationship (chi square $\left(\chi^{2}\right) ; p=0.024$ ) was found; these results prove that males are more affected by inflammatory odontogenic cysts and females are more affected by developmental odontogenic cysts. Regarding anatomical site, the mandibular region was affected in $60.5 \%$ of cases and the maxillary region in $39.5 \%$. This is in agreement with literature as only in one study was the maxillary region more affected by developmental odontogenic cyst than the mandibular region. The mean age of patients affected by developmental odontogenic cyst was almost 45 years old and similar data have been found in other studies present in literature [11-33]. Out of 30 neoplastic odontogenic cysts, $66.7 \%$ of patients (20) were male. These data are in agreement with other similar studies by Ali MA et al. [13], Luo HY et al. [34] but contrary to those found for inflammatory and developmental cysts, they did not represent a statistically significant relationship; this suggests that both males and females are equally affected by this type of lesion. Regarding the site, the mandibular region was affected in $66.7 \%$ of cases and the maxillary region in $33.3 \%$ and this figure is in line with literature. The mean age of patients suffering from neoplastic odontogenic cyst was almost 42 years old and similar data have been found in other studies present in literature $[13,27,33]$. In all three types of lesions, the anatomic site did not correlate in any statistically significant way. These data reveal that, while they present different anatomical characteristics, maxillary and mandibular regions can be affected by different types of odontogenic cysts with the same probability. This could be due to the fact that the infective process affects upper and lower teeth with the same probability in inflammatory odontogenic cysts and an associated unerupted tooth can be indifferently found in the maxillary or mandibular region regarding developmental cysts or a neoplastic process can indifferently originate in the maxillary or mandibular region. Concerning age of patients, there is no statistically significant relationship with all types of odontogenic cysts. In detail, the range goes from childhood to old age with a mean age of 40-50 years old for each type of odontogenic cyst. These data suggest that age did not represent a useful tool in the differentiation of the three subtypes of odontogenic cyst. Regarding the prevalence of the inflammatory lesion with respect to the other two groups of lesions, the results obtained from the current study are similar to those reported by Kammer et al. [35], that found the root cyst as the most prevalent lesion, followed by the odontogenic keratocyst and the dentigerous cyst. On the other hand, data concerning the anatomical localization of the inflammatory cyst show some differences, with the inflammatory cyst affect more frequently the maxilla, while observed malformative cysts sites are in agreement with the results obtained in the current study. Additionally, Kammer et al. [35] found the average age of patients affected by inflammatory cyst to be higher than those affected by malformative cyst, while the present observed an overlap in the average age of patients affected by inflammatory and malformative cysts. In conclusion, this study presents a retrospective comparative analysis of 356 cases of odontogenic cysts. A significant association between odontogenic cystic lesions and patient gender was found. No significant association between histological features of the lesion and age of patient was observed, nor type of odontogenic disease and region (mandibular or maxillary). 
Author Contributions: Conceptualization, A.B. and M.L.; methodology, M.L. and S.R.; formal analysis, A.A.; investigation, G.O.; data curation, A.A.; writing-original draft preparation, A.B. and M.P.; writing-review and editing, A.M. and R.C.; supervision, G.O. All authors have read and agreed to the published version of the manuscript.

Funding: This research received no external funding.

Conflicts of Interest: The authors declare no conflict of interest.

\section{References}

1. Wright, J.M.; Vered, M. Update from the 4th edition of the world health organization classification of head and neck tumours: Odontogenic and maxillofacial bone tumors. Head Neck Pathol. 2017, 11, 68-77. [CrossRef]

2. Soluk-Tekkeşin, M.; Wright, J.M. The world health organization classification of odontogenic lesions: A summary of the changes of the 2017 (4th) Edition. Turk Patoloji Derg. 2018, 34. [CrossRef] [PubMed]

3. Main DMG. Epithelial jaw cysts: A clinicopathological reappraisal. Br. J. Oral Surg. 1970, 8, $114-125$. [CrossRef]

4. Butt, F.M.; Ogeng'o, J.; Bahra, J.; Chindia, M.L. Pattern of odontogenic and non odontogenic cysts. J. Craniofac. Surg. 2011, 22, 2160-2162. [CrossRef] [PubMed]

5. Bilodeau, E.A.; Collins, B.M. Odontogenic cysts and neoplasms. Surg. Pathol. Clin. 2017, 10, 177-222. [CrossRef]

6. Soames, J.V.; Southam, J.C. Patologia Orale; EMSI Edizioni Mediche Scientifiche Internazionali: Roma, Italy, 2005.

7. Sivapathasundharam, B.; Biswas, P.G.; Preethi, S. The World Health Organization classification of odontogenic and maxillofacial bone tumors: An appraisal. J. Oral Maxillofac. Pathol. 2019, 23, 178-186.

8. Sagit, M.; Guler, S.; Tasdemir, A.; Somdas, M.A. Large radicular cyst in the maxillary sinus. J. Craniofac. Surg. 2011, 22, e64-e65. [CrossRef]

9. Bonardi, J.P.; Gomes-Ferreira, P.H.; de Freitas Silva, L.; Momesso, G.A.C.; de Oliveira, D.; Ferreira, S.; dos Santos Pereira, R.; Souza, F.Á. Large dentigerous cyst associated to maxillary canine. J. Craniofac. Surg. 2017, 28, e96-e97. [CrossRef]

10. Chuong, R.; Donoff, R.B.; Guralnick, W. The odontogenic keratocyst. J. Oral Maxillofac. Surg. 1982, 40, 797-802. [CrossRef]

11. Ramachandra, P.; Maligi, P.; Raghuveer, H. A cumulative analysis of odontogenic cysts from major dental institutions of Bangalore city: A study of 252 cases. J. Oral Maxillofac. Pathol. JOMFP 2011, 15, 1-5. [CrossRef]

12. Johnson, N.R.; Savage, N.W.; Kazoullis, S.; Batstone, M.D. A prospective epidemiological study for odontogenic and non-odontogenic lesions of the maxilla and mandible in Queensland. Oral Surg. Oral Med. Oral Pathol. Oral Radiol. 2013, 115, 515-522. [CrossRef] [PubMed]

13. Ali, M.A. Biopsied jaw lesions in Kuwait: A six-year retrospective analysis. Med. Princ. Pract. 2011, 20, 550-555. [CrossRef] [PubMed]

14. Khosravi, N.; Razavi, S.M.; Kowkabi, M.; Navabi, A.A. Demographic distribution of odontogenic cysts in Isfahan (Iran) over a 23-year period (1988-2010). Dent. Res. J. 2013, 10, 162-167. [CrossRef] [PubMed]

15. Avelar, R.L.; Antunes, A.A.; Carvalho, R.W.; Bezerra, P.G.; Neto, P.J.O.; Andrade, E.S. Odontogenic cysts: A clinicopathological study of 507 cases. J. Oral Sci. 2009, 51, 581-586. [CrossRef] [PubMed]

16. Tekkesin, M.S.; Olgac, V.; Aksakalli, N.; Alatli, C. Odontogenic and nonodontogenic cysts in Istanbul: Analysis of 5088 cases. Head Neck 2012, 34, 852-855. [CrossRef]

17. Kilinc, A.; Gundogdu, B.; Saruhan, N.; Yalcin, E.; Ertas, U.; Urvasizoglu, G. Odontogenic and nonodontogenic cysts: An analysis of 526 cases in Turkey. Niger. J. Clin. Pract. 2017, 20, 879-883. [CrossRef]

18. Sharifian, M.J.; Khalili, M. Odontogenic cysts: A retrospective study of 1227 cases in an Iranian population from 1987 to 2007. J. Oral Sci. 2011, 53, 361-367. [CrossRef]

19. Açikgöz, A.; Uzun-Bulut, E.; Özden, B.; Gündüz, K. Prevalence and distribution of odontogenic and nonodontogenic cysts in a Turkish population. Med. Oral Patol. Oral Cir. Bucal. 2012, 17, e108-e115. [CrossRef]

20. Kambalimath, D.H.; Kambalimath, H.V.; Agrawal, S.M.; Singh, M.; Jain, N.; Anurag, B.; Michael, P. Prevalence and distribution of odontogenic cyst in Indian population: A 10-year retrospective study. J. Maxillofac. Oral Surg. 2014, 13, 10-15. [CrossRef] 
21. Villasis-Sarmiento, L.; Portilla-Robertson, J.; Melendez-Ocampo, A.; Gaitan-Cepeda, L.A.; Leyva-Huerta, E.R. Prevalence and distribution of odontogenic cysts in a Mexican sample. A 753 cases study. J. Clin. Exp. Dent. 2017, 9, 531-538. [CrossRef]

22. Tortorici, S.; Amodio, E.; Massenti, M.F.; Buzzanca, M.L.; Burruano, F.; Vitale, F. Prevalence and distribution of odontogenic cysts in Sicily: 1986-2005. J. Oral Sci. 2008, 50, 15-18. [CrossRef] [PubMed]

23. Selvamani, M.; Donoghue, M.; Basandi, P.S. Analysis of 153 cases of odontogenic cysts in a South Indian sample population: A retrospective study over a decade. Braz. Oral Res. 2012, 26, 330-334. [CrossRef] [PubMed]

24. Grossmann, S.M.; Machado, V.C.; Xavier, G.M.; Moura, M.D.; Gomez, S.R.; Aguiar, M.C.F.; Mesquita, R.A. Demographic profile of odontogenic and selected nonodontogenic cysts in a Brazilian population. Oral Surg. Oral Med. Oral Pathol. Oral Radiol. Endod. 2007, 104, 35-41. [CrossRef] [PubMed]

25. Ochsenius, G.; Escobar, E.; Godoy, L.; Peñafiel, C. Odontogenic cysts: Analysis of 2944 cases in Chile. Med. Oral Patol. Oral Cir. Bucal. 2007, 12, 85-91.

26. Prockt, A.P.; Schebela, C.R.; Maito, F.D.; Sant'Ana-Filho, M.; Rados, P.V. Odontogenic cysts: Analysis of 680 cases in Brazil. Head Neck Pathol. 2008, 2, 150-156. [CrossRef]

27. Soluk Tekkesin, M.; Tuna, E.B.; Olgac, V.; Aksakallı, N.; Alatlı, C. Odontogenic lesions in a pediatric population: Review of the literature and presentation of 745 cases. Int. J. Pediatr. Otorhinolaryngol. 2016, 86, 196-199. [CrossRef]

28. Mosqueda-Taylor, A.; Irigoyen-Camacho, M.E.; Diaz-Franco, M.A.; Torres-Tejero, M.A. Odontogenic cysts. Analysis of 856 cases. Med. Oral. 2002, 7, 89-96.

29. Zhang, L.L.; Yang, R.; Zhang, L.; Li, W.; MacDonald-Jankowski, D.; Poh, C.F. Dentigerous cyst: A retrospective clinicopathological analysis of 2082 dentigerous cysts in British Columbia, Canada. Int. J. Oral Maxillofac. Surg. 2010, 39, 878-882. [CrossRef]

30. Yeo, J.F.; Rosnah, B.Z.; Ti, L.S.; Zhao, Y.Y.; Ngeow, W.C. Clinicopathological study of dentigerous cysts in Singapore and Malaysia. Malays. J. Pathol. 2007, 29, 41-47.

31. Lin, H.P.; Wang, Y.P.; Chen, H.M.; Cheng, S.J.; Sun, A.; Chiang, C.P. A clinicopathological study of 338 dentigerous cysts. J. Oral Pathol. Med. 2013, 42, 462-467. [CrossRef]

32. Li, N.; Gao, X.; Xu, Z.; Chen, Z.; Zhu, L.; Wang, J.; Liu, W. Prevalence of developmental odontogenic cysts in children and adolescents with emphasis on dentigerous cyst and odontogenic keratocyst (keratocystic odontogenic tumor). Acta Odontol. Scand. 2014, 72, 795-800. [CrossRef] [PubMed]

33. De Avila, E.D.; de Molon, S.R.; Massucato, E.M.; Hochuli-Vieira, E. Relationship between the prevalence of the dentigerous cyst and the odontogenic keratocyst tumor and the current etiologic hypothesis. J. Craniofac. Surg. 2009, 20, 2036-2040. [CrossRef]

34. Luo, H.Y.; Li, T.J. Odontogenic tumors: A study of 1309 cases in a Chinese population. Oral Oncol. 2009, 45, 706-711. [CrossRef] [PubMed]

35. Kammer, P.V.; Mello, F.W.; Rivero, E.R.C. Comparative analysis between developmental and inflammatory odontogenic cysts: Retrospective study and literature review. Oral Maxillofac. Surg. 2020, 24, 73-84. [CrossRef] [PubMed]

Publisher's Note: MDPI stays neutral with regard to jurisdictional claims in published maps and institutional affiliations.

(C) 2021 by the authors. Licensee MDPI, Basel, Switzerland. This article is an open access article distributed under the terms and conditions of the Creative Commons Attribution (CC BY) license (http://creativecommons.org/licenses/by/4.0/). 